\title{
ORIGINAL ARTICLE \\ Molecular and quantitative signatures of biparental inbreeding depression in the self-incompatible tree species Prunus avium
}

\author{
C Jolivet ${ }^{1}, M$ Rogge $^{2}$ and B Degen ${ }^{1}$
}

Genetic diversity strongly influences populations' adaptability to changing environments and therefore survival. Sustainable forest management practices have multiple roles including conservation of genetic resources and timber production. In this study, we aimed at better understanding the variation in genetic diversity among adult and offspring individuals, and the effects of mating system on offspring survival and growth in wild cherry, Prunus avium. We analysed adult trees and open pollinated seed-families from three stands in Germany at eight microsatellite loci and one incompatibility system locus and conducted paternity analyses. Seed viability testing and seed sowing in a nursery allowed further testing for the effects of pollen donor diversity and genetic similarity between mates on the offspring performance at the seed and seedling stages. Our results were contrasting across stands. Loss of genetic diversity from adult to seedling stages and positive effect of mate diversity on offspring performance occurred in one stand only, whereas biparental inbreeding depression and significant decrease in fixation index from adults to seedlings was detected in two stands. We discussed the effects of stand genetic diversity on the magnitude of biparental inbreeding depression at several life-stages and its consequences on the management of genetic resources in $P$. avium.

Heredity (2013) 110, 439-448; doi:10.1038/hdy.2012.103; published online 5 December 2012

Keywords: biparental inbreeding depression; pollen competition; clonal propagation; genetic resources; Prunus avium

\section{INTRODUCTION}

Management of forest species in the long term is a great challenge, given the multiple roles of forest stands. Genetic diversity influences tree species' capacity for adaptation to environmental changes and resistance to pest and pathogen outbreaks. Furthermore, conservation of genetic resources in wild populations is important, as high genetic diversity in wild populations could provide useful genepool for cultivar genetic improvement. Therefore, management strategies should take into consideration the genetic diversity and quality (Hosius et al., 2006) of forest reproductive material.

Patterns of genetic variation have been extensively studied in forest species (Pautasso, 2009). Tree species are mostly outcrossed, exhibit strong intra-population genetic variation but low differentiation among populations at molecular levels (Petit and Hampe, 2006). In contrast, quantitative traits often exhibit clinal variation as a result of local adaptation (Hall et al., 2007).

In self-compatible species with a mixed mating system, outcrossing rates tend to increase over life-stages because of late-acting selfincompatibility or inbreeding depression (Hufford and Hamrick, 2003; Naito et al., 2005; Ward et al., 2005; Ishida, 2006; Isagi et al., 2007; Naito et al., 2008; Hasegawa et al., 2009; Tamaki et al., 2009; Philipp and Nielsen, 2010; Kamm et al., 2011), that is, that offspring stemming from self-fertilization will experience reduced fitness. In obligate outcrossing species, biparental inbreeding (that is, mating of two genetically related individuals), might also reduce offspring viability and quality (Nason and Ellstrand, 1995; Teixeira et al., 2009). Therefore, it has been suggested that outcrossing evolved in most tree species to avoid deleterious effects of inbreeding depression (Petit and Hampe, 2006; Duminil et al., 2009) and this might have resulted in the high intra-population genetic diversity in tree species. Yet, only a few studies addressed inbreeding depression in tree species in the wild, mostly due to the long life-span of these species, preventing detailed monitoring of offspring fitness until reproductive life-stage. Although inbreeding depression can be assessed through comparison of inbred and outbred individuals, estimation of biparental inbreeding further requires a measure of genetic similarity. Although, a few authors varied crossing distance between parents and assumed that spatial genetic distance occurred, a more precise and straight forward method is to estimate kinship among parents following paternity analysis (Chaves et al., 2011). Addressing together realized mating patterns and quantitative variation in offspring should thus allow better understanding of the effects of biparental inbreeding on offspring genetic diversity and fitness.

However, strong pollen competition levels through multiple pollen donors (Snow, 1990; Paschke et al., 2005) or pollen density on the style (Armbruster and Rogers, 2004), may favour siring by superior genotypes, and result in higher offspring fitness. In the case of increased realized amount of pollen donors, we would expect that both biparental inbreeding depression and pollen competition positively affect offspring genetic diversity, as biparental inbreeding

1Johann Heinrich von Thünen Institut (vTI), Institute of Forest Genetics, Grosshansdorf, Germany and ${ }^{2}$ Landesbetrieb Wald und Holz NRW, Arnsberg, Germany Correspondence: Dr C Jolivet, Johann Heinrich von Thünen Institut (vTI), Institute of Forest Genetics, Sieker Landstrasse 2, D-22927 Grosshansdorf, Germany. E-mail: celine.jolivet@vti.bund.de

Received 8 February 2012; revised 18 June 2012; accepted 27 August 2012; published online 5 December 2012 
depression reduces the amount of individuals resulting from the mating between genetically related parents. However, strong competitive ability of a few good pollen donors would result in the opposite effect on genetic diversity. Therefore, quality and diversity of the offspring is strongly affected by biparental inbreeding depression and pollen donor abundance and diversity.

Wild cherry, Prunus avium (L.) (Rosaceae), is used as a timber species and occurs in Europe, Western Asia and Northern Africa (Ducci and Santi, 1997) in mixed deciduous forests. The species is light-demanding and individuals are scattered. Adult trees can live up to 100 years and flowering generally occurs for diameter at breast height of $4 \mathrm{~cm}$. P. avium reproduces sexually and auto-fertilization is prevented by a gametophytic incompatibility system (Granger, 2004; De Cuyper et al., 2005; Schueler et al., 2006; Marchese et al., 2007; Vaughan et al., 2008). This means that two individuals carrying the same genotype at the S-locus will not be compatible. Pollen is dispersed by bees, and seeds by gravity and birds, resulting in low dispersal distances (Granger, 2004; Schueler, 2005; Stoeckel, 2006) and consequently in significant spatial genetic structure (Vaughan et al., 2007b; Jolivet et al., 2011). Vegetative propagation through rootsuckering commonly occurs and, as a consequence, clusters of clonal individuals can be identified within the stands (Ducci and Santi, 1997; Schueler, 2005; Schueler et al., 2006; Vaughan et al., 2007a; Jolivet et al., 2011). Although mating patterns have been extensively studied (Schueler, 2005; Stoeckel, 2006; Cottrell et al., 2009), their effect on offspring fitness has not been studied yet.

$P$. avium has been used for reforestation for the last decades and produces highly valuable timber. Furthermore, germplasm conservation is of great value, as it may provide useful genetic variation for cherry cultivars. Therefore, management strategies should optimize both genetic diversity and quality of reproductive material for forestry purposes. High genetic variation, and in particular excess of heterozygosity in mature trees have been reported P. avium (Stoeckel et al., 2006). Although heterosis effects could have lead to heterozygote excess in the adult stage, the authors conclude this is rather a consequence of clonal propagation because fixation indexes did not significantly differ among seeds and adults. In fact, simulations studies also showed that fixation indexes decreased with rate of clonal propagation (Jolivet and Degen, 2011). However, these studies did not address the effects of genetic relatedness between mates on offspring performance. Lack of significant differences in fixation index from seeds to adults in the population analysed (Stoeckel et al., 2006), could result from sampling patterns, population structure or stand management. Indeed, $P$. avium stands can differ in rate of clonal propagation, extent of spatial genetic structure and patterns of pollen dispersal (Stoeckel, 2006; Jolivet et al., 2011), and variation in paternal success within stands also occurs (Cottrell et al., 2009). This calls for more comprehensive studies taking into account mating patterns, clonal propagation and offspring fitness to unravel mechanisms underlying the distribution of heterozygosity in P. avium.

In this study, we addressed biparental inbreeding depression and the effects of the number of pollen donors and diversity on offspring growth and survival in three $P$. avium stands utilized for production of forest reproductive material. In particular, we aimed at answering the following questions: (1) Does loss of genetic diversity occur along life-stages? (2) Is offspring performance affected by genetic similarity between mates and among genetic similarity of pollen donors? (3) How is offspring performance affected by clonal propagation? We further discuss the implication of the present results for conservation of genetic resources in wild cherry.

\section{MATERIALS AND METHODS}

\section{Study plots}

Three $P$. avium natural stands currently used by foresters for seed regeneration were studied. They are located in Germany, in three different regions (Figure 1) and consisted of mixed deciduous forests. The Brandenburg stand was an isolated forest fragment of 50 ha, whereas the Bayern and North Rhine Westfalia (NRW) stands were plots within a larger forest, of respectively 13 and 7.6 ha. In winter 2008-2009, we sampled in each plot leaves or buds from all cherry individuals with a diameter at breast height superior to $4 \mathrm{~cm}$ and recorded spatial coordinates (Table 1). In summer 2008, seeds were sampled from 38 to 40 seed-trees per population by the foresters. Seed-trees represented the source individuals used by foresters for seed regeneration. Of the seeds collected, a first sample was used for seed quality testing, a second for genetic analysis and a third for planting in common garden.

\section{Seed quality testing and nursery}

Seed viability was estimated with a Tetrazolium test (Santos et al., 2007) on 200 seeds per seed-tree. Analyses were conducted for each stand by a local certified laboratory for seed quality testing and seed certification according to the ISTA rules (International Seed Testing Association).

A few days after fruit harvesting in the stands, fruit flesh was removed and seeds were dried at $20-25{ }^{\circ} \mathrm{C}$ until water content reached $9 \%$. The seeds were then stored at $-5^{\circ} \mathrm{C}$. Seed stratification started in January 2009 and consisted of 2 weeks storage at $20^{\circ} \mathrm{C}$ then at $4{ }^{\circ} \mathrm{C}$ in moist conditions. The nursery was located in Bad Waldliesborn (NRW, Germany) and was characterized by sandy soil. In May 2009, seeds were sown by hand in $1 \times 100 \mathrm{~m}$ plots consisting of five $2 \mathrm{~cm}$ deep drills, with a seed density of 100 per running metre. In autumn 2009, we sampled leaves from 24 seedlings per seed-tree for genetic analysis and root pruning was conducted to ensure even dormancy. In March 2010, seedlings were uprooted and stored at $4{ }^{\circ} \mathrm{C}$. In May 2010, seedlings were again planted in seedbeds consisting of five rows separated by $25 \mathrm{~cm}$, with a density of 12-14 per running metre. In autumn 2010, seedling survival, height and root collar diameter were measured.

\section{Genetic analysis}

DNA from adult trees, saplings and seeds was isolated according to Dumolin et al. (1995). The DNA was quantified on a NanoDrop system (Thermo Fisher Scientific, Schwerte, Germany) and diluted to a standardized DNA concentration of $10 \mathrm{ng}^{-1} \mathrm{l}^{-1}$. We amplified eight microsatellite loci (Testolin et al., 2000; Dirlewanger et al., 2002; Schueler et al., 2003), using the combinations and conditions described in Jolivet et al. (2011), with the only difference being the labelling from primers UDP98_411 (FAM), UDP98_412 (FAM) and BPPCT_040 (HEX). Fragments were analysed on a Megabace genetic analyser (Amersham Biosciences, Buckinghamshire, UK) using the Megabace ET 400-R size standard (GE Healthcare, Munich, Germany). Allele binning and scoring was performed with the software MegaBace Fragment Profiler v1.2 (Amersham Biosciences). Microsatellite loci were controlled for presence of null alleles, large allele dropout and stuttering errors on adult genotypes with MicroChecker v 2.2.3 (Van Oosterhout et al., 2004). No misbehaviour was detected, therefore we used all microsatellite loci for further analysis.

Gametophytic incompatibility system genotypes were characterized for all adults and seeds, by amplification of the first intron of the S-RNase gene and the S-haplotype-specific F-box (SFB) $5^{\prime}$ untranslated region intron and fragment analysis, following Vaughan et al. (2008). Fragments were run on a Megabace genetic analyser (Amersham Biosciences) using the Megabace ET 550-R size standard (GE Healthcare). When amplification of the SFB intron was not successful and the S-allele could not be identified, we also amplified the second intron of the S-RNase gene (Sonneveld et al., 2003; Vaughan et al., 2008). We used $60 \mathrm{ng}$ DNA, $2.5 \mu \mathrm{l} 10 \times$ Buffer, $2 \mathrm{mM} \mathrm{MgCl}_{2}, 0.2 \mathrm{~mm}$ dNTP $0.2 \mathrm{~mm}$ of each forward and reverse primer, $1.25 \mu \mathrm{lW}-1$ buffer (Invitrogen, Darmstadt, Germany) and $1.25 \mathrm{U}$ Taq polymerase for a total reaction volume of $25 \mu$ l. PCR was conducted with the following conditions: 2 min denaturing at $94^{\circ} \mathrm{C}$, followed by 10 cycles of $10 \mathrm{~s}$ at $94^{\circ} \mathrm{C}, 2 \mathrm{~min}$ at $58^{\circ} \mathrm{C}$ and $2 \mathrm{~min}$ at $68^{\circ} \mathrm{C}$, then 25 cycles of $10 \mathrm{~s}$ at $94^{\circ} \mathrm{C}, 2 \mathrm{~min}$ at $58^{\circ} \mathrm{C}$ and $2 \mathrm{~min}$ at $68^{\circ} \mathrm{C}$, with an increment of the last step of $10 \mathrm{~s}$ at each cycle. The fragments were separated 


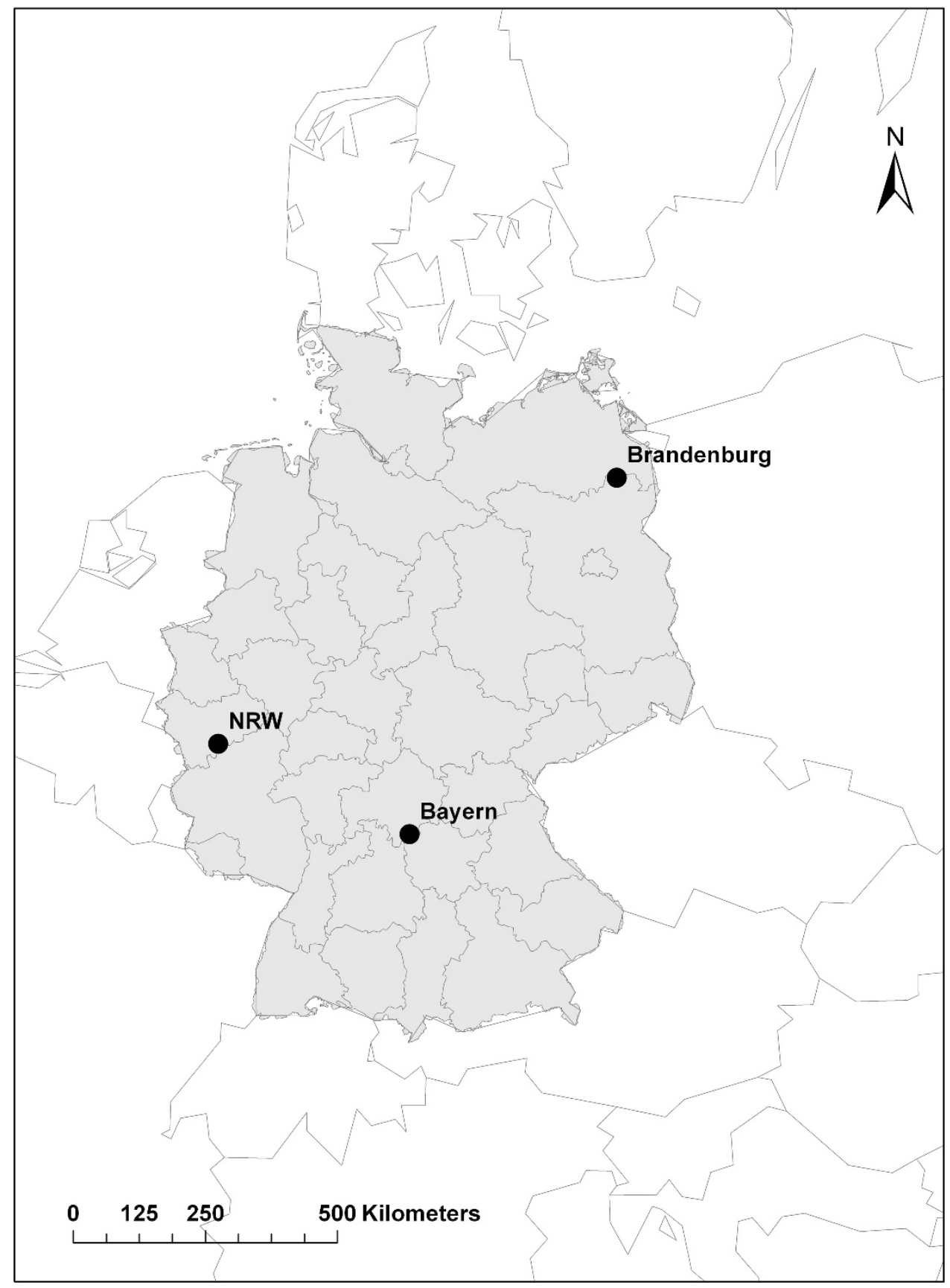

Figure 1 Map of the three P. avium stands (Bayern: $49.623^{\circ} \mathrm{N}-10.192^{\circ} \mathrm{E}$; NRW: $50.608^{\circ} \mathrm{N}-6.939^{\circ} \mathrm{E}$; Brandenburg: $53.477^{\circ} \mathrm{N}-13.719^{\circ} \mathrm{E}$ ) included in the study.

on a $1.3 \%$ agarose gel for $16 \mathrm{~h}$ at $60 \mathrm{~V}$. For both methods, alleles were identified according to Vaughan et al. (2008).

\section{Statistical analysis}

Genetic diversity. As asexual reproduction occurs in wild cherry, we compared genotypes of individual trees at the eight microsatellite loci and at the S-locus among adults to detect clonal ramets. We allowed one mismatch among genotypes to take into account genotyping errors. In all subsequent analysis, we removed all ramets of the same clone and replaced them by a single virtual individual to which was attributed the most frequent genotype, the largest diameter at breast height and the centroïd as spatial coordinates. All seed-trees were considered as single individuals for mating parameters estimation, even if ramets of the same clone were sampled.

We first addressed genetic diversity within life-stages in each stand. To take into account the effect of rare alleles, we estimated the effective number of alleles $A_{\mathrm{e}}$ per locus. To take into account variation in sample size and sampling effects on observed diversity, we also report allelic richness $A_{\mathrm{r}}$ (ElMousadik and Petit, 1996). We conducted paired $t$-tests on $A_{\mathrm{e}}$ and $A_{\mathrm{r}}$ per microsatellite locus among life-stages to address genetic erosion in seeds and seedlings.

As genotypes at the S-locus are always heterozygous, we only calculated the fixation index $F$ based on microsatellite markers. Significance was tested with 10000 randomizations of alleles among individuals within-populations (null hypothesis, $F=0$ ). A significant positive value indicates an excess of 
Table 1 Number of individuals and families sampled per ontogenic stage for genetic analysis in the three $P$. avium stands studied

\begin{tabular}{lccc}
\hline & $\begin{array}{c}\text { Bayern } \\
13 \text { ha }\end{array}$ & NRW & Brandenburg \\
& & & 50 ha \\
\hline & & & \\
Adults & 504 & 510 & 455 \\
$\quad$ Number of individuals ( $)$ & 192 & 362 & 347 \\
Number of genotypes (ng) & 0.38 & 0.71 & 0.76 \\
Clonal diversity (ng $N^{-1}$ ) & 34 & 51 & 21 \\
Number of clonal genotypes & $10.2(2-122)$ & $3.9(2-12)$ & $6.14(2-20)$ \\
Average number of ramets & & & \\
(min-max) & & & \\
& & & \\
Seeds & 38 & 39 & 40 \\
Number of families & 760 & 780 & 800 \\
Number of seeds & & & \\
& & & \\
Seedlings & 37 & 39 & \\
$\quad$ Number of families & 888 & 936 & 960 \\
Number of seedlings & & & \\
\hline
\end{tabular}

Abbreviation: NRW, North Rhine Westfalia.

homozygotes, whereas a significant negative value indicates an excess of heterozygotes. As selection against inbred individuals could lead to a decrease in fixation index in older individuals, we tested for variation in fixation index among ontogenic stages with paired $t$-tests on per-locus estimates. All genetic parameters were estimated with Fstat v. 2.9.3.2 (Goudet, 1995) and GDA_NT (Degen, unpublished), statistical analysis were conducted with $\mathrm{R}$ v 2.0.6 (R Development Core Team, 2004).

Paternity analysis. We conducted paternity analysis on seeds to estimate mating patterns with CERVUS v. 3.0.3 (Marshall et al., 1998; Kalinowski et al., 2007). Allele frequencies were estimated from the adult group. Simulations were conducted with 50000 offspring, 20 candidate fathers and 1\% genotyping errors. Number of candidate fathers was based on direct and indirect estimates of the number and effective number of fathers per seed-tree (Jolivet et al., 2012). Selfing was not allowed. We considered that $60 \%, 90 \%$ and $90 \%$ of the candidate fathers were sampled in Bayern, NRW and Brandenburg, respectively. Paternity of a given seed was assigned to the compatible candidate father showing the highest LOD score (logarithm (base of 10) of odds), based on the eight microsatellite loci and on the S-locus, with a minimum of six loci genotyped. Seeds for which no compatible father was assigned by the software with a confidence of $95 \%$ were excluded. Only one mismatch at the microsatellite loci was allowed and genotypes were controlled individually to distinguish potential genotyping errors, by instance, because of stuttering. No mismatch was allowed at the S-locus.

The unbiased effective number of fathers (K) (Nielsen et al., 2003) was addressed in each seed-tree to provide an indication of diversity sampled by seed-trees. As spatial genetic structure is common in wild cherry stands (Jolivet et al., 2011) and might result in biparental inbreeding, we also estimated the average kinship (Loiselle et al., 1995) per seed-tree among mothers and fathers, as well as the average kinship among male gametes within each seed-tree. The analysis was conducted with SpaGedi v 1.3c (Hardy and Vekemans, 2002). Kinship among mother and fathers provides an estimate of genetic relatedness among parents and might allow detecting the expected level of inbreeding in offspring, whereas the kinship among male gametes provides an estimate of the genetic diversity sampled by seed-trees, independent of paternity analysis.

Offspring fitness. We tested whether the matting system has an effect on offspring fitness (seed viability, seedling survival, seed mass, seedling height and diameter). For each response variable, we conducted a multiple regression including kinship among seed-tree and father, kinship among male gametes and effective number of fathers. We used generalized linear models with binomial errors for seed viability and seedling survival, and linear models with response variable transformation, when necessary, for seed mass, seedling height and diameter. We used analysis of deviance and model simplification to find the minimum adequate model.

\section{RESULTS}

\section{Genetic diversity and structure among life-stages}

Rate of clonal propagation varied among stand, stand Bayern showing lower clonal diversity (Table 1). A low clonal diversity not only indicates a large proportion of clonal individuals, but also that clonal groups include a large number of ramets. Several seed-trees were ramets of the same clone, leaving 19,37 and 30 mother genotypes for Bayern, NRW and Brandenburg, respectively (Supplementary File 1).

Genetic diversity (effective number of alleles and allelic richness) was the strongest in the highly clonally propagated stand Bayern and the lowest in Brandenburg (Table 2) at both microsatellites and S-locus. In the stand Bayern, among adults and seeds, effective number of alleles and allelic richness significantly decreased $\left(A_{\mathrm{e}}: t_{7}=4.18, P=0.004 ; A_{\mathrm{r}}: t_{7}=2.52, P=0.039\right)$, whereas among seeds and seedlings only allelic richness significantly decreased $\left(A_{\mathrm{r}}: t_{7}=4.24, P=0.004\right)$. In stands NRW and Brandenburg, no significant variation in $A_{\mathrm{e}}$ and $A_{\mathrm{r}}$ was observed (all $P$-values $>0.05$ ). Thus, seed sampling resulted in loss of genetic diversity only in the highly clonally propagated and genetically diverse Bayern stand.

Fixation index was mostly negative in stands Bayern and NRW, and showed significant heterozygote excess in seeds and seedlings from Bayern and in adults from NRW. In contrast, significant homozygote excess occurred in seeds and seedlings from Brandenburg (Figure 2, Supplementary Files 2a and b). Fixation index among seeds and adults did not differ significantly in the stand Bayern ( $t$-test, $P>0.1$ ). However, there was a significant decrease in fixation index from seed to adult stages in stands NRW $\left(t_{7}=3.71, P=0.007\right)$ and Brandenburg ( $t_{7}=3.49, P=0.01$; Figure 2$)$. Among adults and seedlings, as well as among seeds and seedlings, no significant variation in fixation index could be observed (all $P$-values $>0.5$ ). This suggests that selection against homozygotes occurs, but it is unclear whether this effect is stronger at early or later life-stages.

\section{Mating patterns}

A father was assigned to $84 \%, 77 \%$ and $92 \%$ of the seeds analysed for Bayern, NRW and Brandenburg, respectively. In stands Bayern and NRW, no relatedness was observed among mates, whereas in stand Brandenburg, average kinship among seed-trees and pollen donors was 0.12 , therefore showing inbreeding in the offspring (Supplementary File 1). In stands NRW and Brandenburg, effective number of fathers was high (31.7 and 34.8, respectively) and kinship among male gametes was similar to the kinship values among mates. In contrast, effective number of fathers was lower in stand Bayern (15.2) and male gametes were related $\left(F_{\mathrm{w}}=0.1\right)$.

For subsequent analysis, estimates of kinship among male gametes, kinship among mates and effective number of fathers were averaged among seed-trees belonging to the same clonal ramet in order to avoid non-independence in the data because of mother genotype effect.

\section{Effects of mate diversity and relatedness on offspring fitness} Within-populations, no difference was detected among clonal and non-clonal seed-trees in seed quality (viability, survival) and seedling size (height, diameter) (Kruskall-Wallis rank sum test, all $P$-values $>0.1$ ). Thus, clonality status of seed-trees does not seem to provide fitness advantage to offspring. We therefore did not include clonality 
Table 2 Effective number of alleles $\left(A_{\mathrm{e}}\right)$ and allelic richness $\left(A_{\mathrm{r}}\right)$ at three ontogenic stages in three $P$. avium stands

\begin{tabular}{|c|c|c|c|c|c|c|c|c|c|c|c|c|c|c|c|c|c|c|}
\hline & \multicolumn{6}{|c|}{ Bayern } & \multicolumn{6}{|c|}{$N R W$} & \multicolumn{6}{|c|}{ Brandenburg } \\
\hline & \multicolumn{2}{|c|}{ Adults } & \multicolumn{2}{|c|}{ Seeds } & \multicolumn{2}{|c|}{ Seedlings } & \multicolumn{2}{|c|}{ Adults } & \multicolumn{2}{|c|}{ Seeds } & \multicolumn{2}{|c|}{ Seedlings } & \multicolumn{2}{|c|}{ Adults } & \multicolumn{2}{|c|}{ Seeds } & \multicolumn{2}{|c|}{ Seedlings } \\
\hline & $A_{e}$ & $\mathrm{~A}_{r}$ & $\mathrm{~A}_{e}$ & $\mathrm{~A}_{r}$ & $A_{e}$ & $\mathrm{~A}_{r}$ & $A_{e}$ & $\mathrm{~A}_{r}$ & $\mathrm{~A}_{e}$ & $\mathrm{~A}_{r}$ & $\mathrm{~A}_{e}$ & $\mathrm{~A}_{r}$ & $\mathrm{~A}_{e}$ & $A_{r}$ & $\mathrm{~A}_{e}$ & $\mathrm{~A}_{r}$ & $\mathrm{~A}_{e}$ & $A_{r}$ \\
\hline \multicolumn{19}{|l|}{ Microsatellites } \\
\hline UDP98_411 & 2.4 & 10.0 & 1.9 & 8.2 & 1.8 & 7.3 & 3.0 & 8.2 & 3.0 & 8.3 & 2.8 & 8.4 & 3.6 & 9.0 & 3.2 & 9.0 & 3.5 & 9.2 \\
\hline BPPCT_040 & 4.2 & 9.0 & 3.2 & 7.7 & 3.3 & 7.6 & 4.1 & 6.0 & 4.4 & 6.7 & 4.2 & 7.0 & 3.4 & 7.0 & 3.4 & 6.0 & 3.1 & 6.2 \\
\hline UDP96_005 & 3.2 & 8.0 & 2.7 & 6.6 & 2.7 & 5.6 & 3.6 & 6.3 & 3.4 & 6.2 & 3.6 & 7.3 & 3.4 & 5.0 & 3.8 & 5.0 & 3.7 & 5.0 \\
\hline UDP96_001 & 2.5 & 6.0 & 2.2 & 6.6 & 2.2 & 5.8 & 1.7 & 4.5 & 1.8 & 3.9 & 1.9 & 3.6 & 2.2 & 3.0 & 2.7 & 3.0 & 2.8 & 3.2 \\
\hline UDP98_021 & 3.0 & 7.0 & 2.4 & 5.6 & 2.4 & 4.8 & 2.1 & 4 & 2.2 & 4.0 & 2.2 & 4.9 & 1.7 & 4.0 & 2.0 & 3.6 & 2.0 & 3.8 \\
\hline UDP98_410 & 3.7 & 9.0 & 3.7 & 9.3 & 3.3 & 8.4 & 3.0 & 6.8 & 2.8 & 5.6 & 2.8 & 5.9 & 2.9 & 5.0 & 2.6 & 4.4 & 2.5 & 5.0 \\
\hline BPPCT_034 & 5.5 & 10.0 & 4.6 & 9.8 & 4.6 & 9.5 & 5.9 & 10.4 & 5.5 & 9.5 & 5.7 & 9.3 & 4.2 & 7.0 & 3.9 & 7.2 & 4.1 & 7.0 \\
\hline
\end{tabular}

Abbreviation: NRW, North Rhine Westfalia.

We analysed eight nuclear microsatellite loci and the gametophytic incompatibility locus.

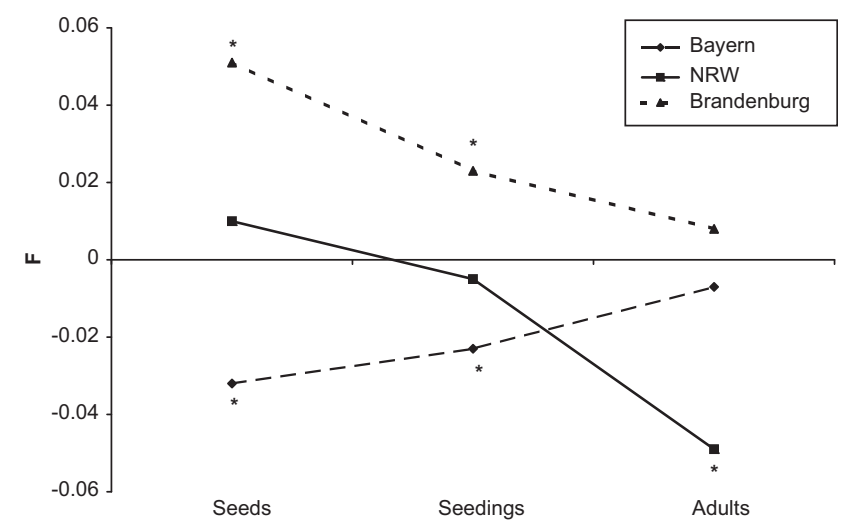

Figure 2 Fixation index among ontogenic stages in three $P$. avium stands. Asterisks indicate significant excess $(F<0)$ or lack $(F>0)$ of heterozygotes.

status in further analysis. Populations differed significantly for all offspring quantitative traits (Kruskall-Wallis rank sum test, all $P$-values $<0.05$; Figure 3).

Mate diversity within seed-families. In the high clonal stand Bayern, seed viability and seedling survival increased significantly with the effective number of fathers, and kinship among male gametes influences negatively seedling survival, thus indicating that diversity sampled by seed-trees positively affected fitness at early life-stages (Table 3). In stand NRW, there were contrasting effects on seedling survival. Survival was negatively influenced by kinship among males, but was lower in families showing high number of effective fathers. The same pattern was observed for seed viability in stand Brandenburg, whereas there was a clear positive effect of kinship among males on seedling survival (that is, negative effect of diversity on seedling survival).

Relatedness among mates. In stand Bayern, seedlings stemming from genetically distant parents were significantly larger (Table 4). Thus, offspring fitness was lower in seedlings from related parents, therefore indicating biparental inbreeding depression at late life-stages. In contrast, seed viability and seedling survival increased with mate genetic similarity indicating rather disadvantage of offspring from genetically unrelated individuals.

In stand NRW, seed viability and seedling survival significantly decreased with kinship among mates, thus indicating biparental inbreeding depression at early life-stages (Table 3), whereas no effect was observed on seedling size.

In stand Brandenburg, offspring from genetically unrelated individuals showed a disadvantage at the earliest life-stage (seed viability), but an advantage at later life-stages (seedling survival and seedling height). This indicates biparental inbreeding depression at late life-stages, although no effect was identified on diameter.

\section{DISCUSSION}

\section{Genetic diversity across life-stages}

In this study, we collected seeds from 40 P. avium seed-trees in three stands in Germany to estimate genetic diversity and quality of seed material. The stand Bayern showed the strongest genetic diversity (effective number of alleles, allelic richness), although rate of clonal propagation was high and one clonal group represented $24 \%$ of the total number of individuals (Table 1). This result is surprising, given that simulation studies on $P$. avium showed a significant decrease in the number of genotypes when clonal propagation was strong, whereas no effect was reported on the effective number of alleles (Jolivet and Degen, 2011). However, the lower diversity in the stand Brandenburg could be explained by its smaller density (Jolivet and Degen, 2011) and its spatial isolation. Although stands Bayern and NRW are located within a continuous forest, stand Brandenburg is a forest fragment surrounded by fields. Habitat fragmentation and absence of fragment connectivity has indeed been reported as a cause for reduced mate availability and increased inbreeding (Fuchs et al., 2003; Lazaro and Traveset, 2006; Campbell and Husband, 2007; Sebbenn et al., 2010; Kamm et al., 2011). Isolation of this P. avium population may have thus resulted in loss of genetic diversity and homozygote excess in seed and seedlings, as a consequence of low pollen immigration (Hanson et al., 2008; Sebbenn et al., 2010), significant spatial genetic structure (see Supplementary File 3; 

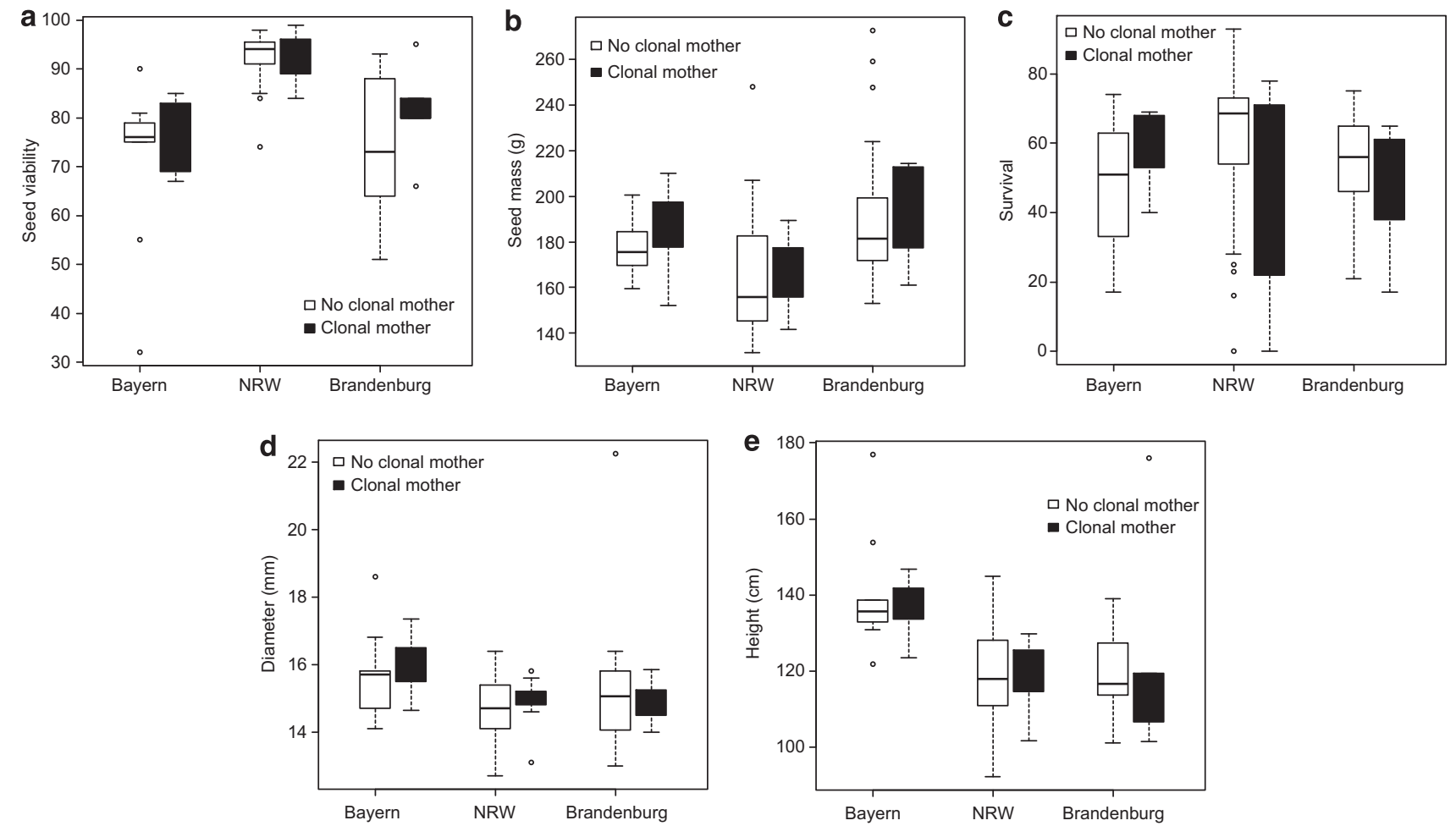

Figure 3 Variation in P. avium seed quality (a) percentage viable seeds, (b) mass of 1000 seeds, (c) percentage survival after 1 year and seedling size (d) diameter, (e) height among seeds and seedlings families stemming from three stands. We differentiate families from clonal and non-clonal seed-trees.

Table 3 Effect of kinship among mates, kinship among male gametes and effective number of father on seed viability and seedling survival in offspring stemming from three $P$. avium stands

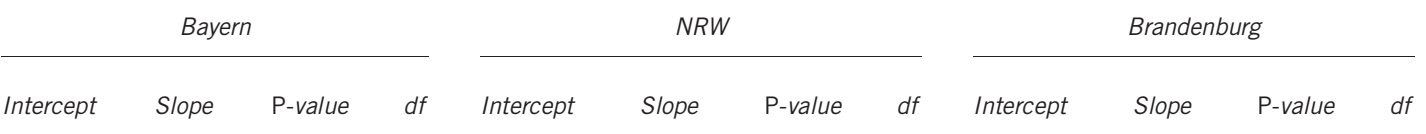

Seed viability

\begin{abstract}
Kinship male-female
Kinship male gametes

Effective number of father

Residuals
\end{abstract}

$\begin{array}{rrr}9.45 & * * * & 1 \\ 1.41 & \# & 1 \\ 0.05 & * * * & 1 \\ & & 15\end{array}$

2.52

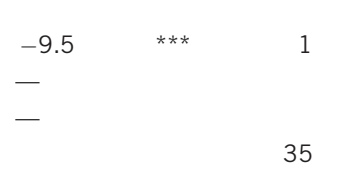

1.29

$\begin{array}{llr}4.74 & * * * & 1 \\ -2.19 & * & 1 \\ -0.007 & * * & 1 \\ & & 26\end{array}$

Survival

$\begin{array}{lrrr}\text { Kinship male-female } & 8.3 & * * * & 1 \\ \text { Kinship male gametes } & -2.14 & * * * & 1 \\ \text { Effective number of father } & 0.02 & * * & 1 \\ \text { Residuals } & & & 14\end{array}$

0.49

$\begin{array}{llr}-9.67 & * * * & 1 \\ -2.40 & * & 1 \\ -0.002 & * & 1 \\ & & 32\end{array}$

$-0.05$

$\begin{array}{ccc}-1.76 & * * * & 1 \\ 1.65 & * * * & 1 \\ - & & \\ & & 27\end{array}$

Abbreviation: NRW, North Rhine Westfalia.

${ }^{\#} P<0.1 ;{ }^{*} P<0.05 ;{ }^{* *} P<0.01 ;{ }^{* * *} P<0.001$.

Statistical analysis was conducted with generalized linear models and binomial errors. Significance was tested with analysis of deviance on the minimum adequate model.

Waser and Price, 1994; Isagi et al., 2007; Grindeland, 2008; Hasegawa et al., 2009; Takeuchi et al., 2010), inbreeding (see Supplementary Material 1) or generation overlapping (Litrico et al., 2005).

Seed sampling and seed germination resulted in loss of genetic diversity in the stand Bayern only. As a consequence of clonal propagation, the number of genotypes among seed-trees was reduced to 19 (see Supplementary File 1). Sampling ramet seed-trees or seed-trees surrounded by many clonal ramets might have affected the genetic composition of the offspring (Charpentier, 2001; Cottrell et al., 2009). Although effective number of fathers was much lower in this stand and that kinship among males gametes was high (Supplementary File 1), this indicates a reduced sampling of diversity by seed-trees. Clonal groups consisting of a large number of clonal ramets might strongly have affected mate availability, but we found 
Table 4 Effect of kinship among mates, kinship among male gametes and effective number of father on seedling height and diameter, in offspring stemming from three $P$. avium stands

\begin{tabular}{|c|c|c|c|c|c|c|c|c|c|c|c|c|c|c|c|}
\hline & Intercept & Slope & P-value & $d f$ & $\mathrm{R}^{2}$ & Intercept & Slope & P-value & $d f$ & $\mathrm{R}^{2}$ & Intercept & Slope & P-value & $d f$ & $\mathrm{R}^{2}$ \\
\hline \multirow[t]{2}{*}{ Height } & $x=1 / x$ & & & & & $X=x$ & & & & & $x=1 / x$ & & & & \\
\hline & & & & & & 116.2 & & & & & 0.008 & & & & \\
\hline Kinship male-female & & - & & & & & - & & & & & 0.005 & ** & 1 & \\
\hline \multirow[t]{2}{*}{ Residuals } & & & & & & & & & 33 & & & & & 28 & \\
\hline & & & & & & & & & & 0.06 & & & & & 0.27 \\
\hline \multirow[t]{2}{*}{ Diameter } & $X=x$ & & & & & $X=x$ & & & & & $X=1 / x^{2}$ & & & & \\
\hline & 16.1 & & & & & & & & & & & & & & \\
\hline Residuals & & & & & 0.41 & & & & & & & & & & \\
\hline
\end{tabular}

Abbreviation: NRW, North Rhine Westfalia.

${ }^{\sharp} P<0.1 ;{ }^{* *} P<0.01$.

Statistical analysis was conducted with linear models and response variable transformation when necessary. Significance was tested with analysis of deviance on the minimum adequate model.

no significant positive relationship between the effective number of fathers and mate availability (analysis not shown, but see Supplementary File 1). As sampling ramet seed-trees shows contrasting results among stands (no loss of diversity in stand Brandenburg), further work involving simulations could be useful to determine the role of spatial arrangement of mature trees and clonal propagation on the genetic diversity of seed-families.

Seedlings also experienced a reduced allelic richness compared with seeds in this stand, indicating that seed viability and seedling survival affected the genetic composition of the seedling sample. Seeds from one seed-tree (M3) even did not germinate. Loss of genetic diversity could be explained by a reduced fitness in seeds and seedlings leading to mortality, by instance through biparental inbreeding depression (Cheliak et al., 1985; Rajora et al., 2000; Hufford and Hamrick, 2003; Naito et al., 2005; Isagi et al., 2007; Duminil et al., 2009; Hasegawa et al., 2009). However, our data rather showed higher survival of offspring from related parents and fixation index showed excess of heterozygotes.

\section{Effects of mate diversity on offspring fitness}

Strong pollen competition should favour siring by donors providing fitness advantage and consequently increase average offspring fitness. We observed a positive effect of effective number of fathers on seed viability and seedling survival in stand Bayern, whereas contrasting results were observed in stands NRW and Brandenburg. Therefore, our results do not deliver a clear pattern, as also shown in the literature (positive effects: Paschke et al., 2005; Vandepitte et al., 2009; no effects: Snow, 1990). In fact, effect of pollen diversity on offspring performance varies among populations and could be affected by environmental stress (Snow, 1990; Paschke et al., 2005). In our study, we observed a positive effect of pollen diversity in the population exhibiting the smallest effective number of fathers but the highest clonality levels (see Supplementary File 1). Although no correlation among the effective number of fathers and mate availability was detected, mate availability decreased in clonal seed-families (analysis not shown, but see Supplementary File 1) in this stand. Therefore, in this situation, poor-quality pollen might sire more offspring in clonal seed-tree through relaxed pollen competition through the style and induce poorer offspring fitness. However, fitness of offspring from clonal seed-trees in this stand tended to be higher, although not significant. Therefore, it is unlikely that the reduced pollen competition among compatible donors because of clonality levels resulted in positive effects of mate diversity on survival traits.

\section{Fixation indexes}

In stands NRW and Brandenburg, fixation indexes decreased from seeds to adults. Loss of homozygote individuals seems indeed to be common in tree species (Cheliak et al., 1985; Hufford and Hamrick, 2003; Naito et al., 2005; Tamaki et al., 2009) and may result from very intensive competition for seedling establishment (Petit and Hampe, 2006) and heterozygote advantage (heterosis).

Surprisingly, excess of heterozygotes was significant in the seeds and seedlings of stand Bayern and tended to decrease from seeds to adults. High clonal propagation enhances excess of heterozygotes in P. avium (Stoeckel et al., 2006; Jolivet and Degen, 2011), however, this was only tested on mature individuals. Some authors hypothesize (Stoeckel et al., 2006) that excess of heterozygotes in wild cherry is a consequence of fitness advantage of heterozygous clones. If such heterozygote advantage would have occurred in stand Bayern, we would have observed heterozygote excess in adults as well. Therefore, the low fixation index observed in seeds is more likely a consequence of mating patterns in the sampled seed-families. Indeed, gametophytic self-incompatibility prevents mating between two individuals sharing the same S-genotype. Sampled seed-trees were mostly originating from clonal propagation and were surrounded by clonal ramets, which reduced mate availability through incompatibility. This might have induced mating with few but unrelated compatible mates, and favoured heterozygosity in the offspring, at least at loci linked to the S-locus (Stoeckel et al., 2006). Furthermore, our study population was 
a plot within a larger forest. P. avium also occurred outside the study area (Jolivet, personal observation) and pollen flow from outside might have happened, as suggested by the16\% non-assigned seeds. As spatial genetic structure was significant in our study plot (Supplementary File 3), pollen immigration could also have induced heterozygosity in the seeds. Yet, kinship among seed-trees and pollen donors in stand Bayern was not lower than kinship levels observed in stand NRW (see Supplementary File 1), which fails to provide evidence of mating with strongly unrelated pollen donors as a consequence of high clonality levels, or of pollen immigration. Therefore, our results on genetic patterns alone do not provide clear insights on the causes of the low fixation index within seeds in stand Bayern.

\section{Biparental inbreeding depression}

Analysis of offspring fitness at early seed life-stage (seed viability) and seedling life-stage (seedling survival, seedling height and seedling diameter) revealed contrasting patterns across populations. In stand Bayern, survival traits (seed viability and seedling survival) indicated disadvantage of offspring from unrelated individuals, whereas one seedling growth trait (diameter) strongly indicated biparental inbreeding depression. Outbreeding depression at very early lifestages could indeed explain that fixation index tended to be lower in seeds. Offspring fitness might show an optimum over the whole parental dissimilarity range as reported in Ranunculus reptans (Willi and Van Buskirk, 2005), but our results are surprising because outbreeding depression rarely occurs within-population (Waser and Price, 1994; Grindeland, 2008), usually because of low environmental heterogeneity within stands (Frankham et al., 2011). This result might also be an artefact resulting from the high variation of kinship within families (Supplementary Material 1). Surprisingly, fixation index did not decrease from seeds to seedlings, as would have suggested the lower fitness of seedlings from genetically related parents. However, seedlings were sampled for genetic analysis one year before phenotyping and biparental inbreeding depression could have occurred after this sampling or might had not yet resulted in seedling mortality. Yet, absence of heterozygote excess within adults suggests no biparental inbreeding depression effects from seedlings to adults, although the number of loci used in our study might be too low to allow a correlation between inbreeding and heterozygosity (Balloux et al., 2004). Environmental stress could also lead to different expression levels of inbreeding (Waser and Price, 1994; Paschke et al., 2005). The nursery was located in a region differing from the region of origin of the stand for soil, water and climate conditions. This could have exacerbated effects of biparental inbreeding depression because of maladaptation of the seedlings, whereas adult trees on the stand would not have suffered strong environmental stress leading heterosis. Absence of hetererozygote excess in the adults could also have resulted from ancient management strategies of the stand, by instance planting of several seed sources (thus explaining the strong genetic diversity), followed by relaxed selection levels, which would have minimized effects of biparental inbreeding depression.

In stand NRW, we found clear evidence of biparental inbreeding depression at survival traits only. Strong inbreeding depression at early life-stages is very likely a consequence of lethal recessive alleles. In self-compatible species, lethal recessive alleles are expected to be rapidly purged from the population, whereas in outcrossed, and especially self-incompatible species, these will be maintained because of heterozygosity. Therefore, inbreeding depression should be stronger at early life-stages in predominantly outcrossed species (Husband and Schemske, 1996), although this has not always been confirmed in the literature (Nason and Ellstrand, 1995; Teixeira et al., 2009). In contrast, in highly self-fertilized species, inbreeding depression should be higher at late life-stages (Husband and Schemske, 1996; Grindeland, 2008; Tamaki et al., 2009). However, long-lived species, especially woody perennials, tend to accumulate mitotic mutations over individuals' lifespan, thus inducing mild inbreeding depression at late life-stages (Ishida, 2006; Petit and Hampe, 2006; Duminil et al., 2009), and resulting in overall strong selection against inbred individuals (Duminil et al., 2009). In our study, we only addressed offspring fitness until the seedling stage, and biparental inbreeding depression because of mild deleterious mutations may not have affected the offspring yet (Waser and Price, 1994). This probably also explains why biparental inbreeding depression was only detected at later life-stages in seedlings from stand Brandenburg. As homozygote excess was observed in this stand, lethal alleles could have been already purged from the population, by instance through ancient isolation of this stand. In stand NRW, mild biparental inbreeding depression might not have affected seedling fitness yet. As seedlings from each seed-tree have been planted in a stand in June 2011, fitness could further be monitored in the next years.

\section{Effects of seed-tree clonality status}

We also aimed at addressing the effect of seed-tree clonality status on offspring fitness. First, clonal genotypes might provide a selective advantage to the offspring through higher survival of clonal ramets in the stand, thus resulting in overall stronger fitness of seed-families stemming from clonal seed-trees. Second, as strong geitonogamy probably occurs (Charpentier, 2001), we also expected stronger style saturation by non-compatible pollen and stronger competition among compatible pollen donors favouring good pollen donors. We did not detect any fitness advantage of seed-families collected on clonal ramets. However, we only addressed realized pollen dispersal patterns. Therefore, pollen counts on style and pollination experiments would be necessary to further address extent of pollen competition in clonal and non-clonal seed-trees as well as the consequences of style saturation with non-compatible pollen on mating patterns and offspring success.

\section{Implications for conservation of forest genetic resources}

In this study, we analysed genetic diversity and fitness of seed-families stemming from seed-trees used by foresters to produce seed material. Efficient conservation of forest genetic resources requires that no loss of diversity occurs in the sampled reproductive material through sampling effects and biparental inbreeding depression. Estimation of inbreeding depression magnitude together with the underlying mechanisms is therefore of great importance for improved management of certified seed stands. In two of our study stands, fixation indexes decreased in later life-stages. In stand NRW, this effect could be attributed to biparental inbreeding depression at early life-stages, but no loss of genetic diversity was detected. Our results suggest that biparental inbreeding depression in $P$. avium does not strongly affect conservation of genetic resources, but the quality of the seed material. In stand Bayern, we did observe a decrease in diversity in seeds and seedlings, probably resulting from sampling of seed-trees belonging to a very large clonal group and to inbred advantage at early life-stages. This call for a better understanding of the effect of clonal propagation, especially size of clonal groups and spatial arrangement of reproductive trees on open pollinated seed-family genetic diversity. To answer this question, we propose to conduct simulations to provide insights on the effect of seed-tree sampling scheme on offspring genetic diversity. 


\section{DATA ARCHIVING}

Data deposited in the Dryad repository: doi:10.5061/dryad.p1g31.

\section{CONFLICT OF INTEREST}

The authors declare no conflict of interest.

\section{ACKNOWLEDGEMENTS}

We thank Carolin Herzog, Monika Spauszus, Dieter Boedecker, and Matthias Wellern for field work, Christoph Nolte and Rainer Ständer for work in the nursery, Alexandra Meier, Susanne Jelkmann, Stefan Jencsik and Inge Schulze for laboratory work, Jarek Burczyk, Silvio Schueler and three anonymous reviewers for constructive comments on the manuscript. This work was supported by the German Ministry of Food, Agriculture and Consumer Protection (BMELV) (grant MuD-Vorhaben (07/B11009) 'Etablierung einer Standardmethode zur genetisch nachhaltigen Ernte von forstlichem Vermehrungsgut in zugelassenen Beständen').

Armbruster WS, Rogers DG (2004). Does pollen competition reduce the cost of inbreeding? Am J Bot 91: 1939-1943.

Balloux F, Amos W, Coulson T (2004). Does heterozygosity estimate inbreeding in real populations? Mol Ecol 13: 3021-3031

Campbell LG, Husband BC (2007). Small populations are mate-poor but pollinator-rich in a rare, self-incompatible plant, Hymenoxys herbacea (Asteraceae). New Phytol 174 915-925.

Charpentier A (2001). Consequences of clonal growth for plant mating. Evol Ecol 15: 521-530

Chaves LJ, Vencovsky R, Mendonca Silva RS, de Campos Telles MP, Zucchi MI, Guedes Coelho AS (2011). Estimating inbreeding depression in natural plant populations using quantitative and molecular data. Conserv Genet 12: 569-576.

Cheliak WM, Pitel JA, Murray G (1985). Population-structure and the mating system of white spruce. Can J Forest Res 15: 301-308.

Cottrell JE, Vaughan SP, Connolly T, Sing L, Moodley DJ, Russell K (2009). Contemporary pollen flow, characterization of the maternal ecological neighbourhood and mating patterns in wild cherry (Prunus avium L.). Heredity 103: 118-128.

De Cuyper B, Sonneveld T, Tobutt KR (2005). Determining self-incompatibility genotypes in Belgian wild cherries. Mol Ecol 14: 945-955.

Dirlewanger E, Cosson P, Tavaud M, Aranzana MJ, Poizat C, Zanetto A et al. (2002). Development of microsatellite markers in peach [Prunus persica (L.) Batsch] and their use in genetic diversity analysis in peach and sweet cherry (Prunus avium L.) Theor Appl Genet 105: 127-138.

Ducci F, Santi F (1997). The distribution of clones in managed and unmanaged populations of wild cherry (Prunus avium). Can J Forest Res 27: 1998-2004.

Duminil J, Hardy OJ, Petit RJ (2009). Plant traits correlated with generation time directly affect inbreeding depression and mating system and indirectly genetic structure. $B M C$ Evol Biol 9: 177

Dumolin S, Demesure B, Petit RJ (1995). Inheritance of chloroplast and mitochondrial genomes in pedunculate oak investigated with an efficient PCR method. Theor App/ Genet 91: 1253-1256.

EIMousadik A, Petit RJ (1996). High level of genetic differentiation for allelic richness among populations of the argan tree Argania spinosa (L) Skeels endemic to Morocco. Theor Appl Genet 92: 832-839.

Frankham R, Ballou JD, Eldridge MDB, Lacy RC, Ralls K, Dudash MR et al. (2011). Predicting the probability of outbreeding depression. Conserv Biol 25: 465-475.

Fuchs EJ, Lobo JA, Quesada M (2003). Effects of forest fragmentation and flowering phenology on the reproductive success and mating patterns of the tropical dry forest tree Pachira quinata. Conserv Biol 17: 149-157.

Goudet J (1995). FSTAT (Version 1.2): a computer program to calculate F-statistics. $J$ Hered 86: 485-486.

Granger AR (2004). Gene flow in cherry orchards. Theor App/ Genet 108: 497-500.

Grindeland JM (2008). Inbreeding depression and outbreeding depression in Digitalis purpurea: optimal outcrossing distance in a tetraploid. J Evol Biol 21: 716-726.

Hall D, Luquez V, Garcia VM, St Onge KR, Jansson S, Ingvarsson PK (2007). Adaptive population differentiation in phenology across a latitudinal gradient in European Aspen (Populus tremula, L.): a comparison of neutral markers, candidate genes and phenotypic traits. Evolution 61: 2849-2860.

Hanson TR, Brunsfeld SJ, Finegan B, Waits LP (2008). Pollen dispersal and genetic structure of the tropical tree Dipteryx panamensis in a fragmented Costa Rican landscape. Mol Ecol 17: 2060-2073.

Hardy OJ, Vekemans X (2002). SPAGEDi: a versatile computer program to analyse spatial genetic structure at the individual or population levels. Mol Ecol Notes 2: 618-620.

Hasegawa Y, Suyama Y, Seiwa K (2009). Pollen donor composition during the early phases of reproduction revealed by DNA genotyping of pollen grains and seeds of Castanea crenata. New Phytol 182: 994-1002.

Hosius B, Leinemann L, Konnert M, Bergmann F (2006). Genetic aspects of forestry in the central Europe. Eur J For Res 125: 407-417.
Hufford KM, Hamrick JL (2003). Viability selection at three early life stages of the tropical tree, Platypodium elegans (Fabaceae, Papilionoideae). Evolution 57: 518-526.

Husband BC, Schemske DW (1996). Evolution of the magnitude and timing of inbreeding depression in plants. Evolution 50: 54-70.

Isagi Y, Saito D, Kawaguchi H, Tateno R, Watanabe S (2007). Effective pollen dispersal is enhanced by the genetic structure of an Aesculus turbinata population. J Ecol 95: 983-990.

Ishida K (2006). Maintenance of inbreeding depression in a highly self-fertilizing tree, Magnolia obovata thunb. Evol Ecol 20: 173-191.

Jolivet C, Degen B (2011). Spatial genetic structure in wild cherry (Prunus avium L.): II. Effect of density and clonal propagation on spatial genetic structure based on simulation studies. Tree Genet Genomes 7: 541-552.

Jolivet C, Holtken AM, Liesebach H, Steiner W, Degen B (2011). Spatial genetic structure in wild cherry (Prunus avium L.): I. Variation among natural populations of different density. Tree Genet Genomes 7: 271-283.

Jolivet C, Holtken AM, Liesebach H, Steiner W, Degen B (2012). Mating patterns and pollen dispersal in four contrasting wild cherry populations (Prunus avium L.). Eur J For Res 131: 1055-1069.

Kalinowski ST, Taper ML, Marshall TC (2007). Revising how the computer program CERVUS accommodates genotyping error increases success in paternity assignment. Mol Ecol 16: 1099-1106.

Kamm U, Gugerli F, Rotach P, Edwards P, Holderegger R (2011). Genetic consequences of low local tree densities - implications for the management of naturally rare, insect pollinated species in temperate forests. Forest Ecol Manag 262: 1047-1053.

Lazaro A, Traveset A (2006). Reproductive success of the endangered shrub Buxus balearica Lam. (Buxaceae): pollen limitation, and inbreeding and outbreeding depression. Plant Syst Evol 261: 117-128.

Litrico I, Ronfort J, Verlaque R, Thompson JD (2005). Spatial structure of genetic variation and primary succession in the pioneer tree species Antirhea borbonica on La Reunion. Mol Ecol 14: 1575-1584.

Loiselle BA, Sork VL, Nason J, Graham C (1995). Spatial genetic-structure of a tropical understory shrub, Psychotria officinalis (Rubiaceae). Am J Bot 82: 1420-1425.

Marchese A, Tobutt KR, Raimondo A, Motisi A, Boskovic RI, Clarke J et al. (2007). Morphological characteristics, microsatellite fingerprinting and determination of incompatibility genotypes of Sicilian sweet cherry cultivars. J Hortic Sci Biotechnol 82: $41-48$.

Marshall TC, Slate J, Kruuk LEB, Pemberton JM (1998). Statistical confidence for likelihood-based paternity inference in natural populations. Mol Ecol 7: 639-655.

Naito Y, Kanzaki M, Iwata H, Obayashi K, Lee SL, Muhammad N et al. (2008). Density-dependent selfing and its effects on seed performance in a tropical canopy tree species, Shorea acuminata (Dipterocarpaceae). Forest Ecol Manag 256: 375-383.

Naito Y, Konuma A, Iwata H, Suyama Y, Seiwa K, Okuda T et al. (2005). Selfing and inbreeding depression in seeds and seedlings of Neobalanocarpus heimii (Dipterocarpaceae). J Plant Res 118: 423-430.

Nason JD, Ellstrand NC (1995). Lifetime estimates of biparental inbreeding depression in the self-incompatible annual plant Raphanus-sativus. Evolution 49: 307-316.

Nielsen R, Tarpy DR, Reeve HK (2003). Estimating effective paternity number in social insects and the effective number of alleles in a population. $\mathrm{Mol} E \mathrm{Col} 12$ : 3157-3164.

Paschke M, Bernasconi G, Schmid B (2005). Effects of inbreeding and pollen donor provenance and diversity on offspring performance under environmental stress in the rare plant Cochlearia bavarica. Basic Appl Ecol 6: 325-338.

Pautasso M (2009). Geographical genetics and the conservation of forest trees. Perspect Plant Ecol Evol Syst 11: 157-189.

Petit RJ, Hampe A (2006). Some evolutionary consequences of being a tree. Annu Rev Ecol Evol Syst 37: 187-214.

Philipp M, Nielsen LR (2010). Reproductive ecology of Scalesia cordata (Asteraceae), an endangered species from the Galapagos Islands. Bot J Linean Soc 162: 496-503.

R Development Core Team (2004). R: a language and environment for statistical computing. Vienna, Austria. ISBN 3-900051-07-0 (http://www.R-project.org).

Rajora OP, Mosseler A, Major JE (2000). Indicators of population viability in red spruce, Picea rubens. II. Genetic diversity, population structure, and mating behavior. Can J Bot 78: 941-956.

Santos MAO, Novembre A, Marcos J (2007). Tetrazolium test to assess viability and vigour of tomato seeds. Seed Sci Technol 35: 213-223.

Schueler S (2005). Pollen-Mediated Gene Flow of Trees in the Temperate Zone. University of Hamburg: Hamburg, Germany.

Schueler S, Tusch A, Scholz F (2006). Comparative analysis of the within-population genetic structure in wild cherry (Prunus avium L.) at the self-incompatibility locus and nuclear microsatellites. Mol Ecol 15: 3231-3243.

Schueler S, Tusch A, Schuster M, Ziegenhagen B (2003). Characterization of microsatellites in wild and sweet cherry (Prunus avium L.) - markers for individual identification and reproductive processes. Genome 46: 95-102.

Sebbenn AM, Carvalho ACM, Freitas MLM, Moraes SMB, Gaino A, da Silva JM et al. (2010). Low levels of realized seed and pollen gene flow and strong spatial genetic structure in a small, isolated and fragmented population of the tropical tree Copaifera langsdorffii Desf. Heredity 106: 134-145.

Snow AA (1990). Effects of pollen-load size and number of donors on sporophyte fitness in wild radish (Raphanus-raphanistrum). Amer Nat 136: 742-758.

Sonneveld T, Tobutt KR, Robbins TP (2003). Allele-specific PCR detection of sweet cherry self-incompatibility (S) alleles S1 to S16 using consensus and allele-specific primers. Theor App/ Genet 107: 1059-1070. 
Stoeckel S (2006). Impact de la propagation aséxuée et du système d'auto-incompatibilite gamétophytique sur la structuration et l'évolution de la diversité génétique d'une essence forestière entomophile et disséminée, Prunus avium L. Cemagref: France.

Stoeckel S, Grange J, Fernandez-Manjarres JF, Bilger I, Frascaria-Lacoste N, Mariette S (2006). Heterozygote excess in a self-incompatible and partially clonal forest tree species - Prunus avium L. Mol Ecol 15: 2109-2118.

Takeuchi Y, Samejima H, Nakagawa M, Diway B, Nakashizuka T (2010). Neighborhood aggregation effect and its effective scale on reproductive success in Shorea laxa (Dipterocarpaceae). J Plant Res 123: 249-259.

Tamaki I, Ishida K, Setsuko S, Tomaru N (2009). Interpopulation variation in mating system and late-stage inbreeding depression in Magnolia stellata. Mol Ecol 18: 2365-2374.

Teixeira S, Foerster K, Bernasconi G (2009). Evidence for inbreeding depression and postpollination selection against inbreeding in the dioecious plant Silene latifolia. Heredity 102: $101-112$

Testolin R, Marrazzo T, Cipriani G, Quarta R, Verde I, Dettori MT et al. (2000). Microsatellite DNA in peach (Prunus persica L. Batsch) and its use in fingerprinting and testing the genetic origin of cultivars. Genome 43: 512-520.
Van Oosterhout C, Hutchinson WF, Wills DPM, Shipley P (2004). MICRO-CHECKER: software for identifying and correcting genotyping errors in microsatellite data. $\mathrm{Mol}$ Ecol Notes 4: 535-538.

Vandepitte K, Roldan-Ruiz I, Honnay O (2009). Reproductive consequences of mate quantity versus mate diversity in a wind-pollinated plant. Acta Oecol 35: 548-553.

Vaughan SP, Boskovic RI, Gisbert-Climent A, Russell K, Tobutt KR (2008). Characterisation of novel S-alleles from cherry (Prunus avium L.). Tree Genet Genomes 4: 531-541.

Vaughan SP, Cottrell JE, Moodley DJ, Connolly T, Russell K (2007a). Clonal structure and recruitment in British wild cherry (Prunus avium L.). Forest Ecol Manag 242 419-430.

Vaughan SP, Cottrell JE, Moodley DJ, Connolly T, Russell K (2007b). Distribution and finescale spatial-genetic structure in British wild cherry (Prunus avium L.). Heredity 98: 274-283.

Ward M, Dick CW, Gribel R, Lowe AJ (2005). To self, or not to self... A review of outcrossing and pollen-mediated gene flow in neotropical trees. Heredity 95: 246-254.

Waser NM, Price MV (1994). Crossing-distance effects in Delphinium-nelsonii - outbreeding and inbreeding depression in progeny fitness. Evolution 48: 842-852.

Willi Y, Van Buskirk J (2005). Genomic compatibility occurs over a wide range of parental genetic similarity in an outcrossing plant. Proc Roy Soc B-Biol Sci 272: 1333-1338.

Supplementary Information accompanies the paper on Heredity website (http://www.nature.com/hdy) 